\title{
Fetal Echocardiography Indications and Lack of Association between Abnormal Exams and Advanced Maternal Age: A Cross-Sectional Study - Fetal Abnormal Echocardiography
}

\section{Indicações para realização de ecocardiografia fetal e ausência de associação entre exames alterados e idade materna avançada: Um estudo transversal - Ecocardiografia fetal anormal}

\author{
Daniela Tarta da Silveira ${ }^{10}$ Cristina Ortiz Sobrinho Valete ${ }^{2(1)}$ Eliane Lucas $^{3(1)}$ \\ Gesmar Volga Haddad Herdy ${ }^{10}$
}

${ }^{1}$ Universidade Federal Fluminense, Niterói, RJ, Brazil

2 Universidade Federal de São Carlos, São Carlos, SP, Brazil

3 Universidade da Serra dos Órgãos, Teresópolis, RJ, Brazil

Rev Bras Ginecol Obstet 2020;42(12):805-810.
Address for correspondence Cristina Ortiz Sobrinho Valete, PhD, Rodovia Washington Luiz, KM 235, SP, 310, São Carlos, SP, 3565-905, Brazil (e-mail: cristina.ortiz@ig.com.br).

\begin{abstract}
Keywords

- congenital heart disease

- prenatal diagnosis

- fetal heart

- fetal ultrasonography

Objective To analyze the most frequent referrals for fetal echocardiography, including advanced maternal age and its association with abnormal results.

Methods We included all pregnant women referred to perform fetal echocardiography (gestational age 22-32 weeks) in 2 health centers in Rio de Janeiro, from June 2015 to June 2016. Advanced maternal age was considered when age was $>35$ years at the time of delivery). Referral reasons and results were recorded, according to the Brazilian Fetal Cardiology Statement. Crude and adjusted prevalence ratios were calculated (Poisson regression). We considered $p<0.05$ as significant.

Results A total of 1,221 tests were analyzed. Abnormal fetal echocardiography was observed in $14.82 \%$ of the cases. The most frequent abnormalities were interventricular septal defect (6.39\%), septal hypertrophy (3.35\%) and atrioventricular septal defect (1.14\%). Routine exams were performed in 559 women, 289 were referred for advanced maternal age and 373 were referred according to the Brazilian Fetal Cardiology Statement criteria. An obstetric ultrasound suggesting fetal cardiac abnormality, maternal diabetes, increased nuchal translucency, and obstetric ultrasound suggesting a noncardiac abnormality were strongly associated with an abnormal fetal echocardiography. Abnormal results were not more frequent in women with advanced maternal age when compared with the rest of the study group.

Conclusions It was observed that routine exams and advanced maternal age referrals were very frequent. Those exams were not associated to fetal echocardiography abnormalities. In this scenario, when the obstetric ultrasound suggests a fetal cardiac
\end{abstract}

received

April 13, 2020

accepted

August 12, 2020
DOI https://doi.org/

10.1055/s-0040-1718445. ISSN 0100-7203.
Copyright $\odot 2020$ by Thieme Revinter

Publicações Ltda, Rio de Janeiro, Brazil
License terms

(c) (i) 


\section{Resumo}

\section{Palavras-chave \\ - cardiopatias \\ - cuidado pré-natal \\ - coração fetal \\ - ultrassonografia pré- natal}

abnormality, the fetal echocardiography probably is abnormal. Therefore, obstetric ultrasound is a good screening method.

Objetivo Analisar as indicações mais frequentes para realização de ecocardiografia fetal, incluindo idade materna avançada, e a associação destas com exames alterados. Métodos Foram incluídas todas as gestantes que realizaram ecocardiografia fetal na idade gestacional entre 22 e 32 semanas, em 2 centros de referência no Rio de Janeiro, no período de junho de 2015 a junho de 2016. Foi considerada idade materna avançada se no momento do parto a idade materna fosse $>35$ anos. As indicações e os resultados dos exames foram registrados, segundo a Diretriz Brasileira de Cardiologia Fetal. Foram calculadas as razões de prevalência brutas e ajustadas através da regressão de Poisson, considerando-se $p<0,05$.

Resultados Um total de 1.221 exames foram analisados. A frequência de exame ecocardiográfico alterado foi $14,82 \%$. As alterações mais frequentes foram defeito do septo interventricular (6,39\%), hipertrofia septal $(3,35 \%)$ e defeito do septo atrioventricular $(1,14 \%)$. Quinhentos e cinquenta e nove exames foram realizados com indicação de rotina, 289 por idade materna avançada e 373 preenchiam critério de acordo com a Diretriz Brasileira de Cardiologia Fetal. O exame ecocardiográfico alterado foi associado ao ultrassom obstétrico sugerindo cardiopatia fetal, ao diabetes materno, à translucência nucal aumentada e ao ultrassom obstétrico sugerindo alteração extracardíaca. Não foi observada maior frequência de exame ecocardiográfico alterado nas gestantes com idade materna avançada, comparado ao restante da amostra.

Conclusão Constatou-se elevada frequência de indicações de rotina, e por idade materna avançada isoladamente, que não foram associados a alterações da ecocardiografia fetal. Em nosso meio, quando o ultrassom obstétrico sugere cardiopatia fetal, é muito provável que a ecocardiografia fetal também seja anormal. Portanto, o ultrassom obstétrico é um bom método de rastreio pré-natal.

\section{Introduction}

Congenital cardiac anomalies occur in $\sim 8$ to 18 per 1,000 live births. Research shows that 3 to $4 \%$ of live births have major heart defects that require intervention during the $1^{\text {st }}$ year of life. ${ }^{1}$ The frequency of congenital heart defects is six times higher than chromosomal defects and four times higher than neural tube defects. ${ }^{2,3}$ These anomalies are responsible for up to $10 \%$ of deaths in children. ${ }^{1,4}$ Fetal diagnosis of cardiac anomalies can improve the prognosis and contribute to the reduction of infant morbidity and mortality, directing expectant mothers to specialized centers. ${ }^{1,5}$

There is still no criterion based on scientific evidence to indicate a fetal echocardiography scan for all pregnant women. ${ }^{6}$ The American Heart Association published a protocol in 2014 with recommendations for screening of pregnant women considered at high risk. According to this, when the risk of cardiac alteration exceeds $3 \%$, fetal echocardiography should be performed; when the risk is $>2$ to $3 \%$, the test should be considered. ${ }^{7}$

More recently, the Brazilian Society of Cardiology has published the Brazilian Guideline of Fetal Cardiology, highlighting the clinical conditions that increase the risk of fetal heart alteration and the indications for a fetal echocardiography scan. ${ }^{8}$

Although advanced maternal age ( $>35$ years at the time of delivery) is an important maternal-fetal risk, associated with maternal hypertension, c-section delivery, prematurity, and low birth weight, such factor alone does not constitute risk of fetal heart alteration and, therefore, is not an indication for fetal echocardiography in the two aforementioned guidelines. ${ }^{7-9}$

The sensitivity of $88.5 \%$ and $100 \%$ specificity of fetal echocardiography in detecting congenital heart abnormalities should be emphasized, which makes this test an important diagnostic tool. ${ }^{10}$

The objective of this study was to analyze the most frequent indications for fetal echocardiography, the alterations found, and if there was an association of advanced maternal age and other factors with abnormal results in two reference centers in Rio de Janeiro.

\section{Methods}

Cross-sectional, analytical study approved by the Research Ethics Committee of Federal Fluminense University, under 
number CAAE: 51113115.1.0000.5243. Informed consent was waived by the ethics board.

Pregnant women with gestational age between 22 and 32 weeks who underwent fetal echocardiography at Hospital Federal de Bonsucesso or at the Clínica Carlos Bittencourt in Rio de Janeiro from June 2015 to June 2016 were included. Cases of fetal heart poorly visualized were excluded.

Fetal echocardiography was performed by the same pediatric cardiologist, using PHILIPS ENVISOR (Philips, Andover MA, USA) and GE VOLUSON E (GE, Milwaukee WI, USA), with transducers sized 5 to $3.3 \mathrm{Mhz}$. All tests showed good visualization of the fetal heart, with apical sections of four and five chambers, short and long axis visualization and visualization of the aortic arch and ductus arteriosus. When necessary, color Doppler evaluation was performed. The assessed outcome was an abnormal fetal echocardiography examination (yes/no), suggesting structural or non-structural/functional cardiac alteration. Advanced maternal age was considered if $>35$ years at the expected delivery date. The indications for the screening were recorded, and all pregnant women with indications in accordance with the Brazilian Fetal Cardiology Guidelines were considered a risk group.

The data were collected retrospectively from medical records and stored in an Excel spreadsheet (Microsoft Corp., Redmond, WA, USA). Statistical analysis was performed using the Stata version 13.0 program (Stata Corp, LLC, College Station, TX, USA). The sample calculation was performed considering power of $80 \%, \alpha$ of 0.05 and $2 \%$ difference in proportion between two groups (high and low risk), resulting in 1,044 subjects. The normality of the variable age was tested by the Shapiro Wilk test. The results are presented in medians and interquartile range (IQR). The frequency of indications for the scan, the altered echocardiography, and the alterations detected were calculated, with their respective $95 \%$ confidence intervals (95\% CIs). Routine indications (regular exams without a specific indication) were analyzed. Differences between proportions were calculated by the chi-squared test. A bivariate analysis was performed with the outcome of the abnormal echocardiographic scan and possible associated variables. Poisson anal- ysis (robust estimation and log-linking function) was performed to estimate crude and adjusted prevalence ratios (CPr and APr). Variables with $p$-value $<0.20$ were included to calculate the adjusted prevalence ratios. For final analyses, $p<0.05$ was considered significant.

\section{Results}

A total of 1,340 scans were performed; 119 were excluded due to poor visualization of the fetal heart. Thus, 1,221 results were analyzed. The average maternal age was 32 years old (IIQ 27-36). The frequency of altered echocardiography was $14.82 \%(181 / 1,221)$. Considering the Brazilian Fetal Cardiology Guidelines, 373 tests (30.54\%) fulfilled the indication criteria, and, of these, 142 (38.06\%) were abnormal. On the other hand, 848 exams (69.45\%) did not meet risk criteria, and, of these, 39 (4.59\%) were abnormal $(p<0.001)$. Advanced maternal age was the isolated indication for 289 tests (23.67\%). Of these, 31 results (10.72\%) were altered. Routine indication was registered in 559 exams.

Among the group of pregnant women who met the criteria according to the Guidelines $(n=373)$, the most frequent indications were an obstetric US suggesting extracardiac alteration (26.2\%), maternal diabetes (18.5\%), and monochorionic twinning (12.6\%). Abnormal results were found more frequently when obstetric US suggested fetal heart disease in 82.35\% of the cases. The most frequent indications and frequency of abnormal results are found in -Table 1.

The most frequent changes were interventricular septal defect, in 6.39\% (78/1,221), septal hypertrophy, in 3.35\% (41/ $1,221)$, and atrioventricular septal defect, in $1.14 \%(14 / 1,221)$. The prevalence and crude prevalence ratio of fetal echocardiographic alterations were calculated according to risk factors (-Table 2).

In the multivariate analysis, the factors associated with higher frequency of altered fetal echocardiography (-Table 3) were maternal diabetes, fetal US suggesting cardiac or extracardiac alteration, and altered nuchal translucency. Advanced maternal age was not maintained in the model ( $p$-value 0.072).

Table 1 More frequent indications for fetal echocardiography and frequency of abnormal results, according to the Brazilian Guideline of Fetal Cardiology

\begin{tabular}{|c|c|c|c|c|}
\hline Indication & $\mathbf{n}$ & Abnormal results & $\%$ & $95 \% \mathrm{Cl}$ \\
\hline Obstetric US suggesting fetal cardiopathy & 34 & 28 & 82.35 & $65.46-93.23$ \\
\hline Chromosomal defects & 20 & 14 & 70 & $45.72-88.10$ \\
\hline Maternal Diabetes & 69 & 22 & 31.88 & $21.17-44.20$ \\
\hline Obstetric US suggesting extracardiac alteration & 98 & 31 & 31.63 & $22.60-41.80$ \\
\hline Increased Nuchal translucency & 27 & 8 & 29.62 & $13.75-50.18$ \\
\hline Cardiac rhythm disorders & 12 & 3 & 25 & $5.48-57.18$ \\
\hline Monochorionic twinning & 47 & 4 & 8.51 & $2.36-20.37$ \\
\hline Others & 66 & 32 & 48.48 & $35.99-61.11$ \\
\hline
\end{tabular}


Fetal Echocardiography Indications and Lack of Association between Abnormal Exams Silveira et al.

Table 2 Prevalence and crude prevalence ratio (CPr) of fetal echocardiographic alterations according to risk factors

\begin{tabular}{|c|c|c|c|c|c|}
\hline Risk factor & $\mathrm{n}$ & $\%$ & Abnormal result (\%) & $\mathrm{CPr}$ & $p$-value \\
\hline \multicolumn{6}{|c|}{ Obstetric US suggesting fetal cardiopathy } \\
\hline Yes & 34 & 2.78 & 82.35 & 7,004 & \multirow[t]{2}{*}{$<0.001$} \\
\hline No & 1,187 & 97.22 & 12.88 & 1 & \\
\hline \multicolumn{6}{|c|}{ Chromosomal defects } \\
\hline Yes & 20 & 1.64 & 70.00 & 5,034 & \multirow[t]{2}{*}{$<0.001$} \\
\hline No & 1,201 & 98.36 & 13.40 & 1 & \\
\hline \multicolumn{6}{|c|}{ Maternal Diabetes } \\
\hline Yes & 69 & 5.65 & 31.88 & 2,310 & \multirow[t]{2}{*}{$<0.001$} \\
\hline No & 1,152 & 94.35 & 13.80 & 1 & \\
\hline \multicolumn{6}{|c|}{ Obstetric US suggesting extracardiac abnormality } \\
\hline Yes & 98 & 8.02 & 31.63 & 3,092 & \multirow[t]{2}{*}{$<0.001$} \\
\hline No & 1,123 & 91.98 & 13.35 & 1 & \\
\hline \multicolumn{6}{|c|}{ Increased nuchal translucency } \\
\hline Yes & 27 & 2.21 & 29.62 & 2,044 & \multirow[t]{2}{*}{0.019} \\
\hline No & 1,194 & 97.78 & 14.48 & 1 & \\
\hline \multicolumn{6}{|c|}{ Cardiac rhythm disorders } \\
\hline Yes & 12 & 0.98 & 25.00 & 1,696 & \multirow[t]{2}{*}{0.295} \\
\hline No & 1,209 & 99.01 & 14.72 & 1 & \\
\hline \multicolumn{6}{|c|}{ Monochorionic twinning } \\
\hline Yes & 47 & 3.84 & 8.51 & 0.922 & \multirow[t]{2}{*}{0.823} \\
\hline No & 1,174 & 96.15 & 15.07 & 1 & \\
\hline \multicolumn{6}{|c|}{ Maternal age alone } \\
\hline Yes & 289 & 23.66 & 10.72 & 0.666 & \multirow[t]{2}{*}{0.029} \\
\hline No & 932 & 76.33 & 16.09 & 1 & \\
\hline
\end{tabular}

Table 3 Adjusted prevalence ratio (Apr) of abnormalities in fetal echocardiography and associated risk factors

\begin{tabular}{llll}
\hline Risk factor & APr & $95 \% \mathrm{Cl}$ & $p$-value \\
\hline Obstetric US suggesting fetal cardiopathy & 6,144 & $4,548-8,302$ & $<0.001$ \\
Maternal Diabetes & 3,508 & $2,378-5,176$ & $<0.001$ \\
Increased nuchal translucency & 3,260 & $1,774-5,992$ & $<0.001$ \\
Obstetric US suggesting extracardiac abnormality & 2,190 & $1,555-3,085$ & $<0.001$ \\
\hline
\end{tabular}

\section{Discussion}

The present study points to the excess of fetal echocardiography tests performed in pregnant women with advanced age without other comorbidities (23.87\%). Although this factor constitutes a maternal-fetal risk, it does not constitute risk of fetal heart alteration. This screening was performed without recommendations supporting it. In the present study, as an isolated factor, a lower prevalence of echocardiographic alterations (CPr 0.66) was observed, not justifying its indication for screening; this recommendation was also published in other articles. $^{9-11}$
The frequency of abnormal results was $14.82 \%$, comparable to the result of Stümpflen et al., ${ }^{12}$ who reported $14.9 \%$ frequency of altered results. The authors studied pregnant women between 18 and 28 weeks who agreed to have the scan performed. ${ }^{12}$ Persico et al. ${ }^{13}$ studied risk pregnancies referred for chorionic villus biopsy and observed $11.6 \%$ of altered results. A national study in pregnant women without risk detected a frequency of $2.5 \%$ of altered tests. ${ }^{14}$ The occurrence of altered results may vary depending on the indications and gestational age when the scan was performed. It is noteworthy that the present study was crosssectional, and the patients were not followed up in the 
postnatal period; all scans were performed during pregnancy.

Considering the altered results in the high-risk group, according to the Brazilian Fetal Cardiology Guidelines, the frequency was $38.06 \%$, while in other indications it was $4.59 \%$, a significant difference that highlights the importance of the adequate indication for fetal echocardiography. On the other hand, Nayak et al. found a high frequency of abnormal results in the group considered low risk, but no difference between high and low risk groups according to the Pediatrics Council of the American Society of Echocardiography. Of interest, the authors reported 26 exams who failed to detect fetal abnormalities on level-2 ultrasound (for poor window, operator error and other reasons). Those exams in other centers probably should have been considered "obstetric ultrasound suggesting a fetal cardiac abnormality." This particular result limits the recommendation that fetal echocardiography should be done in all pregnant women, irrespective of risk factors. ${ }^{15}$ Other studies have found a high frequency of abnormalities in low-risk groups, which raises the need for detailed methodological assessment for proper comparisons. ${ }^{16,17}$ We emphasize the need to follow recommended guidelines to optimize available resources.

In the risk group, the most frequent indication was obstetric US suggesting extracardiac alteration followed by maternal diabetes and monochorionic twinning. Meyer-Wittkopf et al., $^{18}$ in 2001, reported the history of congenital heart disease in the family as the most frequent indication (44.5\%). Friedberg et al. ${ }^{19}$ also reported history of congenital heart disease in the family as the most frequent indication (22\%), followed by maternal diabetes (18\%) and obstetric US suggesting heart disease (13\%). The authors mention that indications for fetal echocardiography have changed over the years as obstetric US has been more accurate, and the high availability of fetal echocardiography may induce indications.

The most frequent echocardiographic change was the interventricular septal defect (6.39\%), followed by septal hypertrophy (3.35\%) and atrioventricular septal defect (1.14\%). Ozkutlu et al. ${ }^{17}$ and Sainz et al. ${ }^{20}$ found similar results. In Porto Alegre, a population-based study with low-risk pregnant women showed interventricular communication as the most frequent alteration, followed by heart rhythm disorders and fetal hypertrophic heart disease. ${ }^{14}$ In our study, it is worth noting that maternal diabetes was the second most frequent indication in pregnant women at risk; septal hypertrophy, a functional change, is associated with this condition. Maternal diabetes is a risk factor for increased left ventricular mass, difficulty in left ventricular relaxation and systolic dysfunction. ${ }^{21,22}$

Factors associated with fetal echocardiographic alterations were obstetric US suggesting fetal heart disease $(\mathrm{APr}=6,144)$, followed by maternal diabetes $(\mathrm{APr}=3,508)$, altered nuchal translucency $(\mathrm{APr}=3,260)$, and obstetric US suggesting extracardiac alterations $(\operatorname{APr}=2,190)$. This result is in accordance with the literature. ${ }^{17,23}$ It is important to stress that we analyzed the most frequent factors to obtain association estimates in our environment. Due to the study design, no direct risk estimates were obtained. Due to the frequency of the altered factors and scans, we opted for $\mathrm{CPr}$ and APr estimates. It is known that in this circumstance, the association estimation by odds ratio may overestimate the association. $^{24}$

This study has limitations. The sample was obtained in two centers where fetal echocardiography was performed, and the study results may not reflect the reality of the city of Rio de Janeiro. In the period studied (2015 and 2016), according to the Superintendence of Health Surveillance, 90,539 and 83,057 live births were recorded, respectively (mean 86,798); thus, the present sample represented $1.4 \%$ of live births in the period. ${ }^{25}$ Also, as a cross-sectional research, no further information on neonatal echocardiography examinations were collected.

\section{Conclusion}

From the results, it was found a high number of scans that did not meet the indication criteria of the Brazilian Fetal Cardiology Guidelines. Special attention should be given to the advanced maternal age, which alone does not constitute fetal risk for cardiac alteration and should not be considered an indication for fetal echocardiography. In our environment, when obstetric US suggests fetal heart disease, it is likely that the fetal echocardiography examination does the same, which reveals the high quality of obstetric US screenings.

\section{Contributions}

All authors participated in the concept and design of the present study; analysis and interpretation of data; draft or revision of the manuscript; and they have approved the manuscript as submitted. All authors are responsible for the reported research.

Conflict of Interests

The authors have no conflict of interests to declare.

\section{References}

1 Cha S, Kim GB, Kwon BS, Bae EJ, Noh CI, Lim HG, et al. Recent trends in indications of fetal echocardiography and postnatal outcomes in fetuses diagnosed as congenital heart disease. Korean Circ J. 2012;42(12):839-844. Doi: 10.4070/kcj.2012.42.12.839

2 Alves Rocha L, Araujo Júnior E, Rolo LC, Barros FSB, Silva KP, Martinez LH, et al. Screening of congenital heart disease in the second trimester of pregnancy: current knowledge and new perspectives to the clinical practice. Cardiol Young. 2014;24(03): 388-396. Doi: 10.1017/S1047951113001558

3 Hunter LE, Simpson JM. Prenatal screening for structural congenital heart disease. Nat Rev Cardiol. 2014;11(06):323-334. Doi: 10.1038/nrcardio.2014.34

4 Allan LD. Echocardiographic detection of congenital heart disease in the fetus: present and future. Br Heart J. 1995;74(02):103-106. Doi: $10.1136 /$ hrt.74.2.103

5 Słodki M, Respondek-Liberska M, Pruetz JD, Donofrio MT. Fetal cardiology: changing the definition of critical heart disease in the newborn. J Perinatol. 2016;36(08):575-580. Doi: 10.1038/ jp.2016.20

6 Wright L, Stauffer N, Samai C, Oster M. Who should be referred? An evaluation of referral indications for fetal echocardiography in the detection of structural congenital heart disease. Pediatr Cardiol. 2014;35(06):928-933. Doi: 10.1007/s00246-014-0877-7 
7 Donofrio MT, Moon-Grady AJ, Hornberger LK, Copel JA, Sklansky MS, Abuhamad A, et al; American Heart Association Adults With Congenital Heart Disease Joint Committee of the Council on Cardiovascular Disease in the Young and Council on Clinical Cardiology, Council on Cardiovascular Surgery and Anesthesia, and Council on Cardiovascular and Stroke Nursing. Diagnosis and treatment of fetal cardiac disease: a scientific statement from the American Heart Association. Circulation. 2014;129(21): 2183-2242. Doi: 10.1161/01.cir.0000437597.44550.5d

8 Pedra SRFF, Zielinsky P, Binotto CN, Martins CN, Fonseca ESVB, Guimarães ICB, et al. Diretriz Brasileira de Cardiologia Fetal. Arq Bras Cardiol. 2019;112(05):600-648. Doi: 10.5935/abc.20190075

9 Mehari MA, Maeruf H, Robles CC, Woldemariam S, Adhena T, Mulugeta $\mathrm{M}$, et al. Advanced maternal age pregnancy and its adverse obstetrical and perinatal outcomes in Ayder comprehensive specialized hospital, Northern Ethiopia, 2017: a comparative cross-sectional study. BMC Pregnancy Childbirth. 2020;20(01): 60. Doi: 10.1186/s12884-020-2740-6

10 Best KE, Rankin J. Is advanced maternal age a risk factor for congenital heart disease? Birth Defects Res A Clin Mol Teratol. 2016;106(06):461-467. Doi: 10.1002/bdra.23507

11 Rocha LA, Araujo Júnior E, Rolo LC, Barros FSB, Silva KP, Leslie ATFS, et al. Prenatal detection of congenital heart diseases: oneyear survey performing a screening protocol in a single reference center in Brazil. Cardiol Res Pract. 2014;2014:175635. Doi: $10.1155 / 2014 / 175635$

12 Stümpflen I, Stümpflen A, Wimmer M, Bernaschek G. Effect of detailed fetal echocardiography as part of routine prenatal ultrasonographic screening on detection of congenital heart disease. Lancet. 1996;348(9031):854-857. Doi: 10.1016/S0140-6736(96)04069-X

13 Persico N, Moratalla J, Lombardi CM, Zidere V, Allan L, Nicolaides $\mathrm{KH}$. Fetal echocardiography at 11-13 weeks by transabdominal high-frequency ultrasound. Ultrasound Obstet Gynecol. 2011;37 (03):296-301. Doi: 10.1002/uog.8934

14 Hagemann LL, Zielinsky P. Rastreamento populacional de anormalidades cardíacas fetais por ecocardiografia pré-natal em gestações de baixo risco no município de Porto Alegre. Arq Bras Cardiol. 2004; 82(04):313-319. Doi: 10.1590/S0066-782X2004000400003

15 Nayak K, Chandra G S N, Shetty R, Narayan PK. Evaluation of fetal echocardiography as a routine antenatal screening tool for detection of congenital heart disease. Cardiovasc Diagn Ther. 2016;6 (01):44-49. Doi: 10.3978/j.issn.2223-3652.2015.12.01
16 Perri T, Cohen-Sacher B, Hod M, Berant M, Meizner I, Bar J. Risk factors for cardiac malformations detected by fetal echocardiography in a tertiary center. J Matern Fetal Neonatal Med. 2005;17 (02):123-128. Doi: 10.1080/14767050500043293

17 Ozkutlu S, Akça T, Kafali G, Beksaç S. The results of fetal echocardiography in a tertiary center and comparison of low- and highrisk pregnancies for fetal congenital heart defects. Anadolu Kardiyol Derg. 2010;10(03):263-269. Doi: 10.5152/akd.2010.068

18 Meyer-Wittkopf M, Cooper S, Sholler G. Correlation between fetal cardiac diagnosis by obstetric and pediatric cardiologist sonographers and comparison with postnatal findings. Ultrasound Obstet Gynecol. 2001;17(05):392-397. Doi: 10.1046/j.14690705.2001.00381.x

19 Friedberg MK, Silverman NH. Changing indications for fetal echocardiography in a University Center population. Prenat Diagn. 2004;24(10):781-786. Doi: 10.1002/pd.981

20 Sainz JA, Zurita MJ, Guillen I, Borrero C, García-Mejido J, Almeida $C$, et al. [Prenatal screening of congenital heart defects in population at low risk of congenital defects. A reality today]. An Pediatr (Barc). 2015;82(01):27-34

21 Dervisoglu P, Kosecik M, Kumbasar S. Effects of gestational and pregestational diabetes mellitus on the foetal heart: a crosssectional study. J Obstet Gynaecol. 2018;38(03):408-412. Doi: 10.1080/01443615.2017.1410536

22 Appiah D, Schreiner PJ, Gunderson EP, Konety SH, Jacobs DJ Jr Nwabuo CC, et al. Association of gestational diabetes mellitus with left ventricular structure and function: the CARDIA Study. Diabetes Care. 2016;39(03):400-407. Doi: 10.2337/ dc15-1759

23 Hernandez-Andrade E, Patwardhan M, Cruz-Lemini M, Luewan S. Early evaluation of the fetal heart. Fetal Diagn Ther. 2017;42(03): 161-173. Doi: 10.1159/000477564

24 Barros AJ, Hirakata VN. Alternatives for logistic regression in cross-sectional studies: an empirical comparison of models that directly estimate the prevalence ratio. BMC Med Res Methodol. 2003;3:21. Doi: 10.1186/1471-2288-3:21-33

25 Prefeitura Municipal do Rio de Janeiro. Secretaria Municipal de Saúde Coordenação de Análise da Situação de Saúde. Indicadores de Saúde de Residentes no Município do Rio de Janeiro, 20102019 [Internet]. 2010 [cited 2020 Jan 12]. Available from: http:// www.rio.rj.gov.br/dlstatic/10112/7629558/4258614/IndicadoresNascimentoeMortalidade2010_2019_MRJ_06_09_19.pdf 